\title{
Racism and urogynecology: what is the connection?
}

\author{
Luiz Gustavo Oliveira Brito $^{1}$. Glaucia Miranda Varella Pereira ${ }^{1}$
}

Received: 23 July 2020 / Accepted: 24 July 2020 / Published online: 8 September 2020

(C) The International Urogynecological Association 2020

We are more than halfway through the year 2020. As a global community, many of us would agree that the last few months have been tough, especially given the novel COVID-19 viral pandemic. As of 3 July 2020, COVID-19 has killed half a million people worldwide [1].

Nevertheless, when we thought that things could not get any worse, George Floyd, a Black man, was killed on 25 May by a white police officer in Minneapolis, Minnesota, for committing a nonviolent crime [2]. Mr. Floyd's death sparked protests about racism, particularly anti-Black racism, in North America, that have spread worldwide.

Racism is a public health problem [3]. There is data showing that racial discrimination, perceived either as a single question or using validated questionnaires on the subject, affects maternal and neonatal outcomes [4]. A cross-sectional national survey of general surgery residents in 2018 reported that $16.6 \%$ experienced racial discrimination; patients and patients' families were the most frequent sources of racial discrimination $(47.4 \%)$ [5].

Moreover, implicit biases can be developed by societal influences that create the perception of our population. A recent study with physicians that work in the acute care surgery arena revealed a high prevalence of implicit bias against Black (49\%) and Hispanic (63\%) people, despite $88 \%$ of the respondents stating that they had no explicit preference for white people [6]. Black surgeons and their professional career are less likely to remain in academia and Black assistant professors have the lowest rates of promotion [7].

Despite equal rights efforts of the last half-century, Black people still suffer the effects of racism, resulting in inequities in health care. Black women have a substantially higher risk of

Luiz Gustavo Oliveira Brito

lgobrito@gmail.com

1 Department of Obstetrics and Gynecology, School of Medical Sciences, University of Campinas, Rua Alexander Fleming, 101-Cidade Universitária, Campinas 13083-881, Brazil severe maternal morbidity and mortality than white women, even adjusting for confounders [8]. Black women are more likely to undergo abdominal hysterectomy, despite a nationwide trend in the USA toward minimally invasive hysterectomy [9]. Within the COVID-19 pandemic, we are seeing substantial racial/ethnic disparities between Black people and white people worldwide [10, 11].

Although a shock to many, Mr. Floyd's death is one of thousands of unnecessary deaths of Black people as a result of structural anti-Black racism. Perhaps Mr. Floyd's unfortunate death will be the final catalyst to spark permanent change. We need to explore this subject in our area; there is a need for addressing racism in our field due to the lack of studies. We do not have data on whether Black women have barriers to access to diagnosis and treatment on urogynecological disorders. Several medical societies published a statement condemning racism and supporting the Black community. These are admirable first steps, but we, as urogynecologists and global citizens, must have intent and take action in our fight to eradicate anti-Black racism. We must admonish racism in all spaces, even those that our Black colleagues, friends, and patients might not inhabit. We need to know our own local data regarding racial disparities and discuss with our multidisciplinary group how to remove barriers to access for these patients. Involving patients in this discussion will be crucial for us to hear their voices. We must continue to study how racism influences the outcome of our urogynecology patients to ensure good-quality and equitable care. We need to be attentive, to advocate for Black women's health, and to ensure that these patients receive the proper diagnosis and treatment.

\section{Compliance with ethical standards}

Conflicts of interest None.

\section{References}

1. Coronavirus. Worldometer, July 3rd $2020 \mathrm{https} / / \mathrm{www}$. worldometers.info/coronavirus/ 
2. Killing of George Floyd. https://en.wikipedia.org/wiki/Killing_of George_Floyd Accessed 3 July 2020.

3. Laurencin CT, Walker JM. Racial profiling is a public health and health disparities issue. J Racial Ethn Health Disparities. 2020;7(3): 393-7. https://doi.org/10.1007/s40615-020-00738-2.

4. Minehart RD, Jackson J, Daly J. Racial differences in pregnancyrelated morbidity and mortality. Anesthesiol Clin. 2020;38(2):27996.

5. Hu YY, Ellis RJ, Hewitt DB, Yang AD, Cheung EP, Moskowitz JT, et al. Discrimination, abuse, harassment, and burnout in surgical residency training. N Engl J Med. 2019;381(18):1741-52.

6. Zebib L, Strong B, Moore G, Ruiz G, Rattan R, Zakrison TL. Association of racial and socioeconomic diversity with implicit bias in acute care surgery. JAMA Surg. 2019;154(5):459-61.

7. Abelson JS, Wong NZ, Symer M, Eckenrode G, Watkins A, Yeo HL. Racial and ethnic disparities in promotion and retention of academic surgeons. Am J Surg. 2018;216(4):678-82.
8. Booker WA, Gyamfi-Bannerman C, Sheen J, Wright JD, Siddiq Z, ME D'A, et al. Maternal outcomes by race for women aged 40 years or older. Obstet Gynecol. 2018;132(2):404-13.

9. McClurg A, Wong J, Louie M. The impact of race on hysterectomy for benign indications. Curr Opin Obstet Gynecol. 2020;32(4):2638.

10. Holmes L Jr, Enwere M, Williams J, Ogundele B, Chavan P, Piccoli T, et al. Black-white risk differentials in COVID-19 (SARS-COV2) transmission, mortality and case fatality in the United States: translation epidemiologic perspective and challenges. Int J Environ Res Public Health. 2020;17(12):E4322.

11. Baqui P, Bica I, Marra V, Ercole A, van der Schaar M. Ethnic and regional variations in hospital mortality from COVID-19 in Brazil: a cross-sectional observational study. Lancet Glob Health. 2020;8(8):e1018-e1026.

Publisher's note Springer Nature remains neutral with regard to jurisdictional claims in published maps and institutional affiliations. 